\title{
Erratum
}

Inflammopharmacology 15 (2007) 266-272

\section{Protective effect of pranlukast, a cysteinyl-leukotriene receptor 1 antagonist, on indomethacin-induced small intestinal damage in rats}

H. Nishio, Y. Hayashi, S. Terashima and K. Takeuchi

Fig. 1 of this article is misprinted. It has to be replaced by the correct one

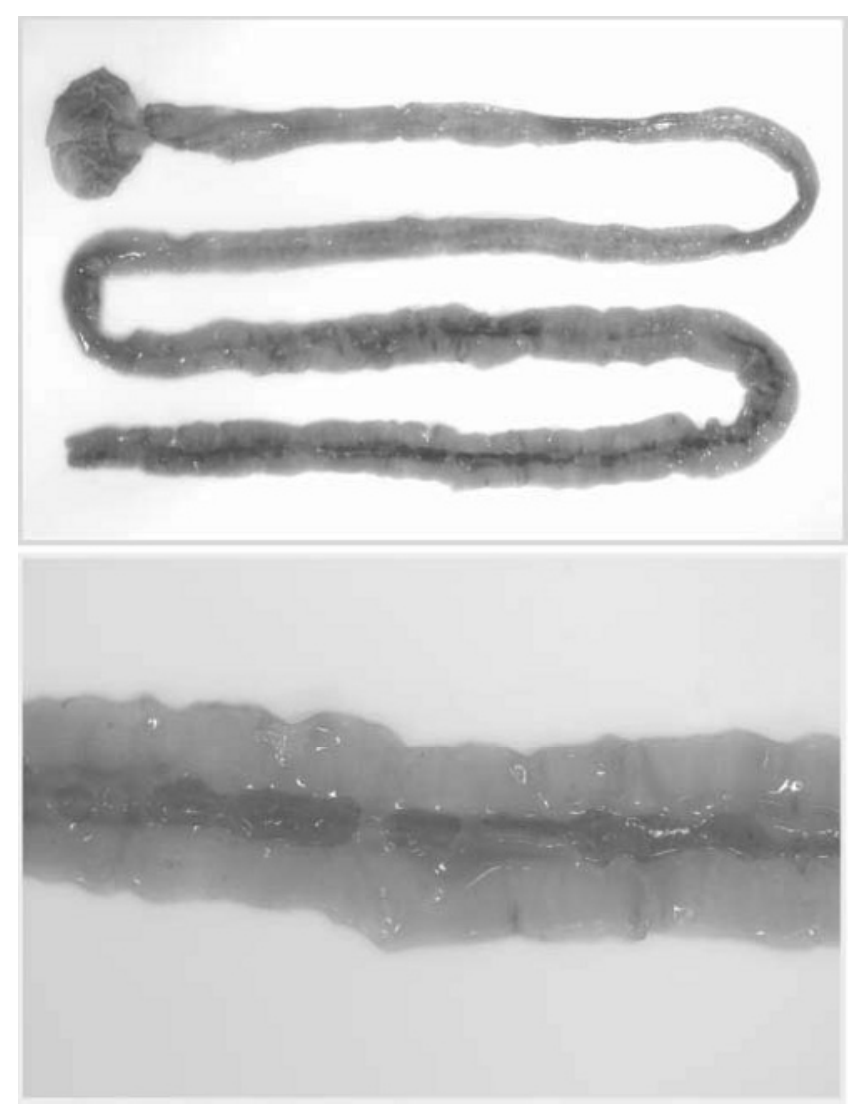

Fig. 1. Macroscopic observations of indomethacin-induced small intestinal lesions in rats. Animals were given indomethacin $(10 \mathrm{mg} / \mathrm{kg})$ s. c., and killed $24 \mathrm{hr}$ later. Note that multiple hemorrhagic lesions occurred in the small intestine, mainly in jejunum and ileum. 